\title{
Selective Induction of Rheumatoid Factors by Superantigens and Human Helper T Cells
}

\author{
Xiaowen He, Jörg Goronzy, and Cornelia Weyand \\ Department of Medicine, Division of Rheumatology, Mayo Clinic and Foundation, Rochester, Minnesota 55905
}

\begin{abstract}
Production of autoantibodies specific for the Fc region of autologous IgG, called rheumatoid factors (RF), is a characteristic finding in patients with rheumatoid arthritis (RA). To study the requirements regulating the synthesis of these autoantibodies, we have cloned human helper $T$ cells and co-cultured them with purified $B$ cells. To mimic cognate $T-B$ cell interaction, we have used bacterial superantigens that function by cross-linking HLA molecules on the B cell with selected $T$ cell receptor (TCR) molecules expressing a particular polymorphism of the $\mathrm{V} \beta$ gene segment. Data presented here demonstrate that the staphylococcal enterotoxin D (SE D), but not other bacterial superantigens, exhibits an ability to induce IgM, IgG, and especially RF production, in B cells from RA patients and normal individuals. Comparison with the polyclonal antibody production in $B$ cell cultures driven by anti-CD3-stimulated $T$ cell clones confirmed that $\mathrm{SE} D$ shifted the repertoire of secreted antibodies toward immunoglobulins with Fc binding specificity, suggesting that SE D preferentially stimulates $\mathrm{RF}^{+} \mathrm{B}$ lymphocytes. B cells with the potential to secrete RF were highly frequent in RA patients, requiring as few as 150 peripheral $B$ cells/culture to detect RF in the culture supernatants. SE D-induced RF synthesis was strictly dependent on the presence of selected $\mathrm{CD4}^{+} \mathrm{T}$ helper cells and required a direct membrane contact between $B$ cells and $T$ helper cells. Here, we propose a model that SE D selectively induces RF production depending on the availability of SE $D$ responsive $T$ cells in the TCR repertoire of the responder. (J. Clin Invest. 1992. 89:673-680.) Key words: rheumatoid arthritis • rheumatoid factor $\bullet B$ cell regulation • staphylococcal enterotoxin
\end{abstract}

\section{Introduction}

Rheumatoid factors (RF) are characteristic, but not pathognomic, autoantibodies of patients with rheumatoid arthritis (RA) (1). They are specific for multiple antigenic determinants in the second and third domains of the immunoglobulin gamma chain constant regions (2). Production of such Fc region binding antibodies is not unique for RA patients. Increased levels of RF have also been described in sera of patients with other autoimmune diseases and are produced by apparently healthy individuals in secondary, $\mathrm{T}$ cell-dependent antibody responses

Address reprint requests to Dr. Weyand, Mayo Clinic, 200 First St., SW, Rochester, MN 55905.

Received for publication 2 July 1991 and in revised form 27 September 1991 .

J. Clin. Invest.

(c) The American Society for Clinical Investigation, Inc.

0021-9738/92/02/0673/08 $\$ 2.00$

Volume 89, February 1992, 673-680
(3-5). Enrichment of precursor B cells able to produce RF have been reported for a distinct subset of $B$ cells which are characterized by the expression of the CD5 molecule $(6,7)$. In RA patients, $\mathrm{CD}^{+} \mathrm{B}$ cells not only produce polyreactive, low affinity autoantibodies, but also monoreactive antibodies with a high affinity for the Fc fragment of the IgG molecule (8).

There is accumulating evidence that RF secretion results from antigen-driven immune responses (9), and that $T$ helper cells play a crucial role in the induction and regulation of the autoantibody synthesis $(10,11)$. However, a specific antigen has not been unequivocally identified that initiates and maintains the production of Fc binding immunoglobulins. Different stimuli have been demonstrated or suggested to support RF production, including the IgG components of antigen antibody complexes, polyclonal B cell stimulators, exogenous antigens expressing cross-reactive determinants to human IgG, and autologous antibodies functioning as anti-idiotypes (9-14). There is no conclusive evidence that any of these mechanisms plays a role in regulating RF synthesis in RA patients.

RA is now understood as a $\mathrm{T}$ cell-mediated disease with a tight genetic linkage that has been mapped to a specific polymorphism of the HLA-DRB1 locus (15-17). The implication of $\mathrm{CD}^{+} \mathrm{T}$ helper cells and antigen-binding HLA molecules in the pathogenesis of the disease has supported a model that endogenous or exogenous antigens might be causative for a pathological immune response leading to RA. Recently, a new mechanism of $T$ cell activation has been described that follows rules distinct from that of antigen-specific, HLA-restricted immune responses. A new class of antigens, so-called superantigens, circumvent antigen-specific $T$ cell stimulation by cross-linking HLA class II molecules and the $T$ cell receptor (TCR) ${ }^{1}$ molecule (18-21). In contrast to mitogens, superantigens do not polyclonally activate all $\mathrm{T}$ cells. Rather, they exhibit a restricted specificity for certain $\mathrm{T}$ cell subpopulations sharing a binding site on the outer surface of the TCR V $\beta$ element ( 22 , 23). Superantigens that are functional in the human immune system are products of bacteria and are highly effective at low concentrations (24). Recently, a direct effect of such bacterial toxins on B cells has been described involving the cross-linking of HLA class II molecules on the surface of B lymphocytes (25, 26). To address the question whether bacterial superantigens trigger the production of $\mathrm{Fc}$ binding autoantibodies, we have established human $\mathrm{CD} 4^{+}$helper $\mathrm{T}$ cell clones and have characterized their response pattern to distinct staphylococcal exotoxins. We have then proceeded to study the ability of such $\mathrm{T}$ cell clones to provide help for the synthesis of RF in T-B cell cultures in the presence of superantigens. Here, we report that we have identified one particular superantigen, staphylococcal enterotoxin D (SE D), which has a unique ability to induce RF

1. Abbreviations used in this paper: HVR, hypervariable region; LCL, lymphoblastoid cell lines; SE D, staphylococcal enterotoxin D; TCR, T cell receptor. 
production in the presence of adequate $T$ cell help. In addition to selectively interacting with particular TCR V $\beta$ segments, SE $\mathrm{D}$ appears to have a functional selectivity to stimulate a discrete subset of B cells supporting a model in which individuals with a particular $\mathrm{T}$ cell repertoire have a higher risk of breaking self-tolerance and producing Fc-binding autoantibodies.

\section{Methods}

Study subjects. Patients with RA were identified through the Division of Rheumatology at the Mayo Clinic and consented to participate in this study. All patients fulfilled the diagnostic criteria for seropositive RA (27). Normal control individuals did not have a personal or family history of inflammatory joint disease and were seronegative for RF. Mononuclear cells were purified from heparinized peripheral blood by Ficoll Hypaque density gradient centrifugation. In general, $\mathrm{T}$ lymphocytes and B cells from freshly separated samples were used for the experiments. In some experiments, cryopreserved $\mathrm{T}$ cells or B cells were utilized after preliminary experiments had demonstrated that they were functionally equivalent to freshly prepared lymphocyte populations.

HLA typing. All donors were characterized for the HLA-DRB1 allele by allele-specific amplification and subsequent oligonucleotide hybridization as described (28). A set of eight distinct primers specific for sequences encoded by the first hypervariable region (HVR) of the HLA-DRB1 locus were used in combination with a nonpolymorphic oligonucleotide (codons 87-93) to amplify the HLA-DRB1 gene in a polymerase chain reaction using the following conditions: 30 cycles, 1 $\min 94^{\circ} \mathrm{C}$ denaturation, $1 \mathrm{~min} 56^{\circ} \mathrm{C}$ annealing, and $2 \mathrm{~min} 72^{\circ} \mathrm{C}$ extension. Amplified templates were subsequently immobilized on nylon membranes and hybridized with oligonucleotides specific for the sequence polymorphisms of the HVR2 or HVR3 of the HLA-DRB1 gene.

Generation of human $T$ cell clones. All T cell clones described in this study were generated by primary stimulation against HLA-DR $\mathrm{B} 1^{*} 0401^{+}\left(\mathrm{HLA}-\mathrm{Dw} 4^{+}\right)$or ${ }^{*} 0404^{+}$(HLA-Dw14 ${ }^{+}$) stimulator cells. 5 $\times 10^{5} \mathrm{PBL} / \mathrm{ml}$ were stimulated with $2.5 \times 10^{5} / \mathrm{ml}$ irradiated stimulator cells. After $1 \mathrm{wk}$, cultures were restimulated and $\mathrm{T}$ cell blasts were cloned at a concentration of 0.3 cells/well in the presence of $3 \times 10^{4} /$ well irradiated filler cells and $20 \mathrm{U} / \mathrm{ml}$ recombinant IL-2. Outgrowing $T$ cell clones were characterized for their specificity by blocking assays with the HLA-DR $\beta 1$-chain specific mAb P4.1 and by panel assays on lymphoblastoid cell lines (LCL) representing the HLA-DR alleles HLA-DR 1 through HLA-DRw 16, including the described subtypes of the HLA-DR4 and HLA-DRw6 families. For these studies, $1-2 \times 10^{4}$ cloned $\mathrm{T}$ cells/well were cultured with $5 \times 10^{4}$ irradiated $L C L$ per well for $48 \mathrm{~h}$. Microcultures were pulsed with $1 \mu \mathrm{Ci}\left[{ }^{3} \mathrm{H}\right]$ thymidine and harvested after an additional $12 \mathrm{~h}$. The majority of $\mathrm{T}$ cell clones used in this study have been characterized for the usage of their TCR V $\beta$ element by utilizing sets of 22 different $\mathrm{V} \beta$ primers combined with a $\mathrm{C} \beta$ primer in a polymerase chain reaction (Weyand, C. M., U. Oppitz, K. Hicok, and J. J. Goronzy. Manuscript submitted for publication; and [28a]). T cell clones were maintained in culture by repeated stimulation with selected allogeneic stimulators in the presence of exogenous IL-2.

Purification of $B$ cells. To collect highly purified populations of B lymphocytes, $5 \times 10^{6} \mathrm{PBL} / \mathrm{ml}$ were incubated in serum free RPMI 1640 with $50 \mathrm{mM}$ L-leucine methyl ester $\mathrm{HCl}$ (Sigma Chemical Co., St. Louis, MO) for $45 \mathrm{~min}$ at room temperature (29). Subsequently, the surviving cell population was incubated with 2-amino-ethylisothuronium-treated sheep red blood cells for $90 \mathrm{~min}$ at $4^{\circ} \mathrm{C}$. Rosetting and nonrosetting populations were separated by centrifugation on Ficoll gradients. Fluorescence activated cell sorter analysis demonstrated that the nonrosetting cells were highly enriched in B cells and contained between 75 and $90 \% \mathrm{CD}^{+} 9^{+}$lymphocytes (data not shown).

Superantigen reactivity of $T$ cell clones. SE A, $C_{1}, C_{2}, C_{3}$, and D were obtained from Toxin Technology (Madison, WI) as lyophilized toxins and were dissolved in RPMI 1640 (30). $2 \times 10^{4}$ rested cloned T cells were stimulated with $5 \times 10^{4} /$ well irradiated $(10,000 \mathrm{rad}) \mathrm{LCL}$ and optimal concentration of SE $(0.5-1 \mu \mathrm{g} / \mathrm{ml})$ in 96 -well plates. Microcultures were pulsed with $\left[{ }^{3} \mathrm{H}\right]$ thymidine after $48 \mathrm{~h}$ and harvested $12 \mathrm{~h}$ later. LCL CRK 077 (HLA-DRB1*0701), which is not recognized by any of the $T$ cell clones in an antigen specific fashion, served as presenting cell for the exotoxins.

In some antibody production experiments, the proliferative response of the same $\mathrm{T}$ cell clones to SE were studied in parallel. In this case, $2 \times 10^{4}$ cloned $\mathrm{T}$ cells were stimulated with $10^{4} \mathrm{~B}$ cells and SE.

Antibody production in T-B cell co-cultures. $10^{5}$ cloned T cells were cultured with purified B cells in 96-well flat bottom tissue culture plates; supernatants were collected after $11 \mathrm{~d}$. If not indicated otherwise, each culture contained 10,000 purified B cells. Controls included cultures that received T cells only, B cells only, T cells and B cells, and $B$ cells together with bacterial superantigens at the concentration of 0.5 $\mu \mathrm{g} / \mathrm{ml}$. T cells were activated by immobilized anti-CD3 monoclonal antibody (mAb), or by bacterial superantigens. In some experiments, B cells were preincubated with $5 \mu \mathrm{g} / \mathrm{ml}$ purified $\mathrm{mAb} \mathrm{L} 243$ which is specific for the HLA-DR $\alpha-\beta 1$ complex. All microcultures were set up in triplicate or quadruplicate. To study the requirement for T-B cell contact, $T$ and B cells were cultured in 24-well plates (Falcon Labware, Lincoln Park, NJ) and separated by a $0.45-\mu \mathrm{m}$ pore size membrane (Cyclopore; Falcon). In these experiments, $\mathrm{T}$ cells were activated by anti-CD3 and B cells incubated with SE D.

Determination of IgM, IgG, and RF. Concentrations of total IgM, IgG, and RF were determined by immunoassay. To measure IgG and IgM, a sheep anti-human polyvalent immunoglobulin (Sigma) was coated to maxisorb plates (Nunc Inc., Naperville, IL) in a carbonate buffer, pH 9.6, at $4^{\circ} \mathrm{C}$ overnight. Remaining binding sites were blocked with 5\% nonfat milk in PBS. Plates were subsequently incubated with diluted supernatants at $4^{\circ} \mathrm{C}$ overnight and then incubated with alkaline phosphate coupled goat anti-human IgG or IgM (Boehringer Mannheim, Indianapolis, IN) for 60-120 min at room temperature. Finally, $P$-nitrophenol phosphate was added in a $10-\mathrm{mM}$ diethanolamine buffer (pH 9.5, 0.5\% $\mathrm{mM} \mathrm{MgCl}$ ). The reaction was read on an ELISA reader at a wavelength of $410 \mathrm{nM}$. Individual immunoassays were standardized by using IgM (Beckman Instruments Inc., Brea, CA) and IgG (Cappel Laboratories, Cochranville, PA) standard solutions. Results are given as the mean.

To determine RF activity, maxisorb plates were coated with human IgG-Fc fragments (Calbiochem-Behring Corp., San Diego, CA) $20 \mu \mathrm{g} /$ $\mathrm{ml}$ in carbonate buffer, $\mathrm{pH} 9.6$, at $4^{\circ} \mathrm{C}$ overnight. The subsequent steps of the immunoassay were identical to the IgG and IgM immunoassays. As a developing antibody, the plates were incubated with alkaline phosphatase-coupled goat anti-human $\kappa$ and $\lambda$ chain specific antisera (Sigma). Each immunoassay was standardized by using pooled serum from RA patients which was kindly standardized by Dr. J. Katzmann, Department of Laboratory Medicine, Mayo Clinic, by nephelometry. To determine the isotype components of RF, plates were coated with purified rabbit IgG. The immunoassays were developed with alkaline phosphatase-coupled anti-human IgM or IgG antiserum as described for total IgM and IgG.

\section{Results}

$R F$ production induced by bacterial superantigens. To study helper cell signals in the activation of RF-producing B cells, we have co-cultured cloned human helper $T$ cells with purified $B$ cells. As shown in Fig. 1, significant concentrations of IgM and IgG antibodies are produced when the $T$ cell clone LAB 1-50 is activated by immobilized anti-CD3. Only an insignificant portion of the antibodies produced exhibits Fc binding properties. To test the hypothesis that cognate interaction between the $T$ cells and B cells might alter the repertoire of secreted antibodies, we have made use of bacterial superantigens. $T$ cell clones 


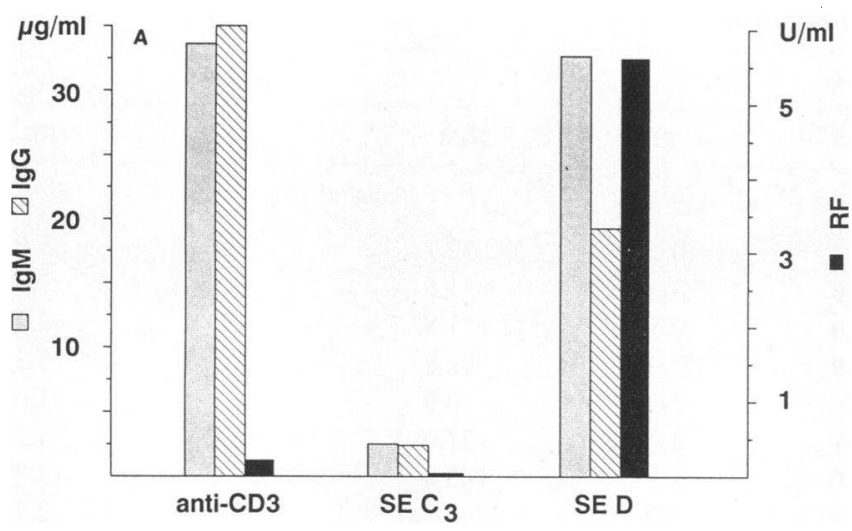

Figure 1. Selective induction of rheumatoid factors by SE D. B lymphocytes were isolated from a normal donor and 10,000 cells/culture were cocultured with $10^{5}$ rested cells of T cell clone LAB 1-50. To initiate stimulation anti-CD3 mAb was coupled to the plates. Parallel cultures received $0.5 \mu \mathrm{g} / \mathrm{ml} \mathrm{SE} \mathrm{C}_{1}$ (not shown), $\mathrm{SE} \mathrm{C}_{3}$, or SE D at the beginning of the culture period. Supernatants were harvested after 11 days and analyzed for $\operatorname{IgM}(\square), \operatorname{IgG}(\mathbb{\otimes})$, and $\operatorname{RF}(\square)$. Control cultures received either cloned $\mathrm{T}$ cells or $\mathrm{B}$ lymphocytes only. Other control cultures received $B$ lymphocytes with the bacterial superantigens in the absence of $\mathrm{T}$ lymphocytes. Immunoglobulin concentrations in control supernatants were below $1 \mu \mathrm{g} / \mathrm{ml}$, RF was essentially undetectable (data not shown).

studied for the helper capabilities to induce $\mathrm{RF}$ production were characterized for their ability to respond to SE A, $C_{1}, C_{2}$, $C_{3}$, and $D$ in a $T$ cell proliferative assay. Response patterns of the $T$ cell clones to the different SE are presented in Table $I$. The individual $T$ cell clones were characterized by a unique SE response pattern which is influenced by the $\mathrm{V} \beta$ element used to assemble their TCR. Subsequently, stimulatory superantigens were included in the T-B cell cultures to mimic a cognate interaction. Surprisingly, the distinct $S E$ were quite different in their effectiveness (Fig. 1). Activation of LAB 1-50 by SE $C_{1}$ and $C_{3}$ induced only low amounts of IgG and IgM antibodies and essentially no RF was synthesized under these conditions although clone LAB 1-50 proliferated to both superantigens presented by B cells (Table I and data not shown). Stimulation of the $T$ cell clone by SE D, however, significantly influenced B cell function. Concentrations of total IgM and IgG were similar to the amounts produced in the anti-CD3 driven cultures, however, the repertoire of antibodies secreted was clearly different. In contrast to the anti-CD3 stimulation, SE D induced high levels of RF.

The distinct effect of $\mathrm{SE}_{3}$ and SE $\mathrm{D}$ as shown in Fig. 1 did not correlate to the induction of $T$ cell proliferation by these two superantigens. In parallel to the T-B cell microcultures assayed for antibody production, $\mathrm{T}$ cell stimulation by $\mathrm{B}$ cells and superantigens was analyzed in a proliferative assay and demonstrated that both enterotoxins induced a similar $\mathrm{T}$ cell proliferation (data not shown). These results suggest that the activation signals provided by stimulation with anti-CD3, and by cross-linking with SE A, $C_{1}, C_{2}, C_{3}$, or D, are not identical and induce a spectrum of biological effects.

$S E D$ induces $R F$ production in normals and patients with $R A$. RF are the characteristic autoantibodies found in patients with RA. Whether the presence of the autoantibodies represents an abnormal function of the B cells, T cells, or of cells of both compartments is essentially unresolved. The hypothesis has been put forward that RA patients have higher frequencies of RF-producing B cells. To study whether SE D-induced RF secretion is different in normal and rheumatoid individuals, we have tested B cells of nine distinct donors for their ability to respond to $T$ cell clone LAB 1-50 when activated by anti-CD3 or SE D. The results are summarized in Table II. All donors were HLA typed; the group of normal donors included four individuals with the genetic susceptibility for RA. None of the normal donors carried RF in the blood or had any evidence of RA. In all donors tested, anti-CD3 stimulation induced the production of IgM and IgG, whereas RF synthesis was minimal. Stimulation of T cell clone LAB 1-50 by SE D resulted in the secretion of IgM and IgG antibodies at concentrations, which generally were similar or lower. B cells of normals, as well as RA patients, produced significant titers of RF ranging from 1.2 to $12.7 \mathrm{U} / \mathrm{ml}$.

Helper cell requirements in $S E D$-induced $R F$ production. The selective induction of RF production in the presence of $S E$ $D$ could reflect the interaction of the bacterial superantigen with a $T$ cell population, a selective effect on a B cell popula-

Table I. Reactivity Patterns of Different Human Helper T Cell Clones to Bacterial Superantigens and Anti-CD3

\begin{tabular}{|c|c|c|c|c|c|c|c|c|}
\hline \multirow[b]{2}{*}{$\begin{array}{l}\mathrm{T} \text { cell } \\
\text { clone }\end{array}$} & \multirow[b]{2}{*}{$\begin{array}{l}\text { TCR V } \beta \\
\text { segment }\end{array}$} & \multicolumn{5}{|c|}{ Proliferative response } & \multirow[b]{2}{*}{$\begin{array}{l}\text { Anti- } \\
\text { CD3 }\end{array}$} & \multirow[b]{2}{*}{$\phi$} \\
\hline & & SE A & $\mathrm{SE} \mathrm{C}_{1}$ & $\mathrm{SE} \mathrm{C}_{2}$ & $\mathrm{SE} \mathrm{C}_{3}$ & SE D & & \\
\hline \multicolumn{9}{|c|}{ cpm } \\
\hline LAB $1-50$ & $\mathrm{~V} \beta 6$ & 2,998 & 39,832 & 2,384 & 35,873 & 17,129 & 23,652 & 706 \\
\hline BAJ $1-107$ & N.I. & 118,535 & 2,046 & 137,509 & 2,038 & 1,870 & 121,566 & 622 \\
\hline STAP 4-404 & $\mathrm{V} \beta 6$ & 33,398 & 2,433 & 1,228 & 6,158 & 3,195 & 89,112 & 255 \\
\hline STAP 4-405 & $\mathrm{V} \beta 6$ & 2,196 & 68,885 & 8,724 & 17,139 & 86,591 & 60,318 & 418 \\
\hline STAP 4-407 & NT & 48,316 & 43,785 & 783 & 37,052 & 39,453 & 71,542 & 483 \\
\hline STAP 4-326 & $\mathrm{NI}$ & 1,690 & 45,738 & 4,195 & 2,193 & 57,649 & 66,416 & 403 \\
\hline STAP 4-357 & $\mathrm{V} \beta 7$ & 41,196 & 1,521 & 1,773 & 1,103 & 1,148 & 50,528 & 499 \\
\hline STAP 4-373 & $\mathrm{V} \beta 6$ & 968 & 1,681 & 1,403 & 94,989 & 1,816 & 93,958 & 466 \\
\hline STAP 4-378 & $\mathrm{V} \beta 2$ & 58,288 & 20,560 & 901 & 55,073 & 40,703 & 32,120 & 512 \\
\hline
\end{tabular}

T cell clones were established from HLA typed donors by allogeneic stimulation of PBL with HLA-B ${ }^{*} 0401^{+}$and ${ }^{*} 0404^{+}$stimulator cells and cloned by limiting dilution. Nonstimulatory irradiated APC were used to establish superantigen reactive proliferative responses. The SE were used at a concentration of $0.5 \mu \mathrm{g} / \mathrm{ml}$ (NI, not identified; NT, not tested). 


\begin{tabular}{|c|c|c|c|c|c|c|c|c|}
\hline \multirow[b]{2}{*}{ Donor } & \multirow[b]{2}{*}{ RA } & \multirow[b]{2}{*}{ HLA-DR } & \multicolumn{3}{|c|}{ Anti-CD3 } & \multicolumn{3}{|c|}{ SE D } \\
\hline & & & IgM & IgG & $\mathbf{R F}$ & IgM & IgG & $\mathbf{R F}$ \\
\hline & & & \multicolumn{2}{|c|}{$\mu g / m l$} & $U / m l$ & \multicolumn{2}{|c|}{$\mu g / m l$} & $U / m l$ \\
\hline SL & - & DR2/5 & 33.6 & 36.1 & 0.2 & 32.7 & 19.3 & 5.6 \\
\hline JJG & - & DR $1 / 7$ & 22.0 & 29.6 & 3.3 & 1.6 & 0.2 & 7.0 \\
\hline PP & - & DR4/w8 & 29.6 & 148.0 & 0.6 & 1.8 & 3.2 & 2.9 \\
\hline JO & - & DR $1 / 7$ & 5.9 & 5.9 & 0.0 & 22.8 & 2.7 & 9.3 \\
\hline KH & - & DR $1 / 4$ & NT & NT & NT & 0.9 & 1.1 & 1.6 \\
\hline NR & - & DR3/3 & 0.2 & 4.1 & 0.02 & 21.0 & 36.1 & 1.2 \\
\hline FE & + & DR3/4 & 123.1 & 119.0 & 0.1 & 143.4 & 127.9 & 12.7 \\
\hline GC & + & DR4 & NT & NT & NT & 0.5 & 0.3 & 2.7 \\
\hline MO & + & DR4/5 & NT & NT & NT & 1.8 & 1.5 & 4.1 \\
\hline
\end{tabular}

B lymphocytes were purified from six normal donors and from three patients with active RA. T-B cell cultures were set up as described above and were either stimulated with immobilized anti-CD3 or $0.5 \mu \mathrm{g} / \mathrm{ml} \mathrm{SE} \mathrm{D.} \mathrm{For} \mathrm{all} \mathrm{experiments,} \mathrm{T} \mathrm{cell} \mathrm{clone} \mathrm{LAB} 1-50$ was used as a source of helper signals. IgM, IgG, and RF concentrations were determined in supernatants harvested afer $11 \mathrm{~d}$.

tion, or a mechanism involving both helper $T$ cells as well as $\mathrm{RF}^{+} \mathrm{B}$ cells. To study whether cell-cell contact is required for the induction of RF, T cells were activated by anti-CD3, B cells were cultured with SE D, and both populations were separated by permeable membranes. The results are shown in Fig. 2 and indicate that a direct T-B cell contact is an absolute requirement for SE D-induced RF synthesis. In the absence of T helper cells, SE D alone was not able to activate B cells to secrete RF. Soluble factors released by the $T$ helper cell clone upon stimulation were apparently not sufficient to enable $B$ cells to produce RF. This interpretation was supported by another set of experiments in which $\mathrm{mAb}$ to the HLA-DR molecules were added to the T-B cell cultures. T cell clones STAP 4-405 and STAP 4-378 were stimulated with immobilized anti-
CD3 and SE D. The addition of anti-HLA-DR mAb signifcantly inhibited RF synthesis, suggesting that HLA-DR molecules play a crucial role in the SE D-induced synthesis of RF (Fig. 3). Interestingly, for some T cell clones, the induction of total IgM and IgG was less sensitive to the inhibitory action of anti-HLA-DR mAb than RF synthesis. There are two distinct explanations for the inhibitory effect of anti-HLA-DR antibodies; either the $\mathrm{mAb}$ prevented the binding of the enterotoxin to the HLA molecules on the antigen presenting B cells, or the $\mathrm{mAb}$ directly interfered with the T-B cell interaction.

$T$ cell help for selective $R F$ production does not require $S E$ $D$-derived proliferation of the $T$ cell clone. To address the question whether effective help for RF-producing $B$ cells required a $\mathrm{SE}$ driven proliferation of the $\mathrm{T}$ cell clone, we selected a CD4 ${ }^{+}$

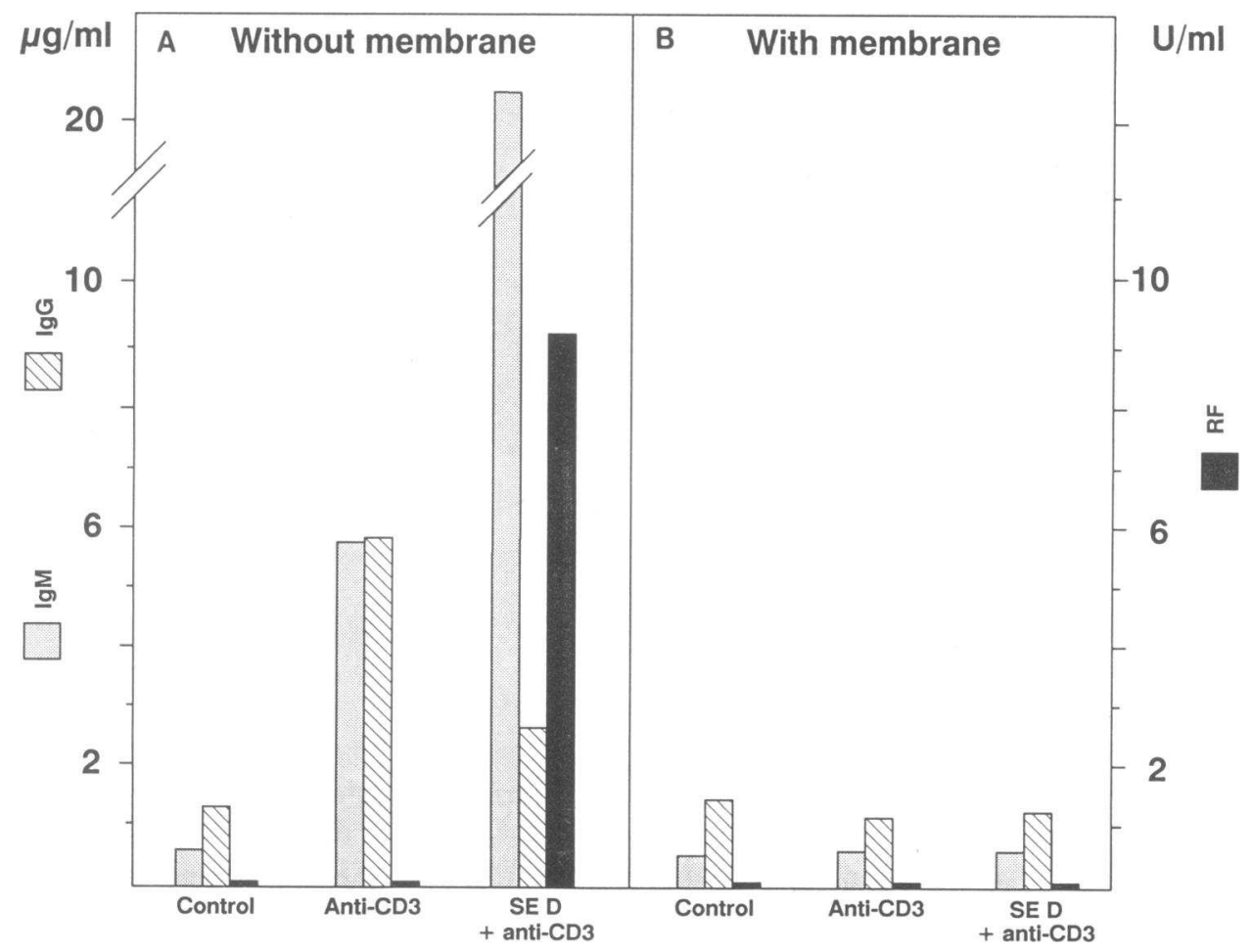

Figure 2. Requirement for direct T$B$ cell contact in SE D-induced RF production. T-B cell cultures were set up as described in Fig. $1(A)$ or were separated by permeable membranes $(B)$. Results are shown for $T$ cell clone LAB 1-50. Cloned T cells were activated by immobilized anti-CD3 and $B$ lymphocytes were incubated with SE $D$ as indicated. Supernatants were harvested at day 11 and analyzed for IgM, IgG, and RF 


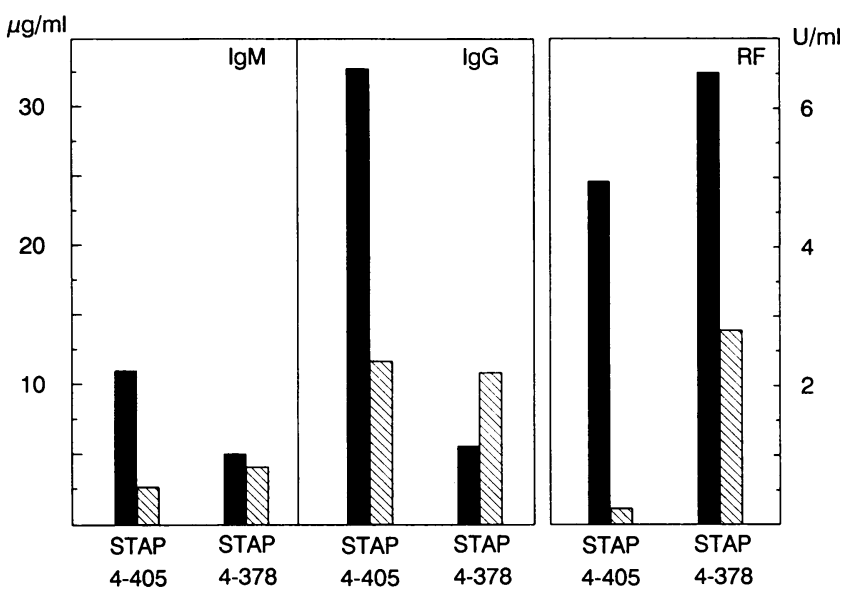

Figure 3. Inhibition of SE D-induced RF synthesis by anti-HLA-DR antibodies. Results are shown from T-B cell cultures utilizing purified B lymphocytes from a normal donor and T cell clones STAP 4-405 or STAP 4-378 which were stimulated with immobilized antiCD3 and SE D $0.5 \mu \mathrm{g} / \mathrm{ml}(\square)$. Parallel cultures $(\mathbb{8})$ received $5 \mu \mathrm{g} / \mathrm{ml}$ of mAb L243 which specifically binds to HLA-DR molecules. RF production was consistently inhibited in the presence of the antiHLA-DR antibody. IgM and IgG production supported by clone STAP 4-405 was significantly reduced as well, whereas immunoglobulin induction by clone STAP 4-378 was unaffected by the antiHLA-DR antibody.

T cell clone, BAJ 1-107, which did not proliferate in response to SE D (Table I). As shown in Fig. 4, activation of clone BAJ 1-107 by immobilized anti-CD3 resulted in the production of high concentrations of IgM and IgG antibodies. The proportion of Fc binding antibodies in the polyclonal IgM/IgG pool was very low. The addition of SE D, however, shifted the repertoire of antibodies produced significantly toward the production of high titers of RF. Again, the T cell clone was absolutely

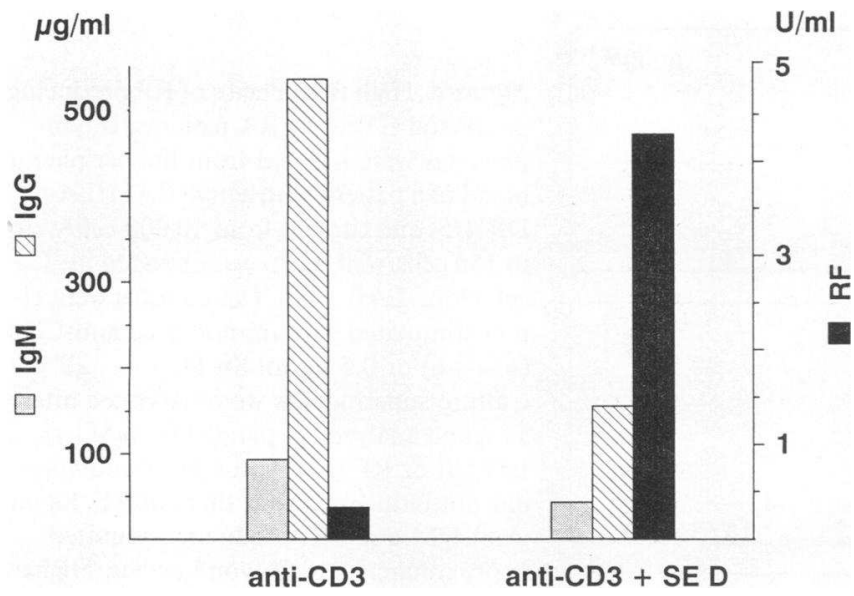

Figure 4. SE D-Induced RF production is independent from SE D induced proliferation of $T$ helper cells. $T$ cell clone BAJ 1-107 does not proliferate in response to SE D (Table I), but provides helper signals for RF secretion. B lymphocytes were cultured with anti-CD3 stimulated cloned $\mathrm{T}$ cells as described. One set of cultures additionally received SE D $(0.5 \mu \mathrm{g} / \mathrm{ml})$. Control cultures without $T$ cells did not produce immunoglobulins (data not shown). The presence of SE D was sufficient to shift the synthesis of immunoglobulins toward RF. necessary for the induction of RF synthesis (data not shown). Although the presence of activated T cells as well as SE D were absolute requirements, the effect did not involve proliferation of the $T$ cell triggered through a SE D-TCR V $\beta$ interaction. The addition of two other superantigens, $\mathrm{SE} \mathrm{A}$ or $\mathrm{SE} \mathrm{C}_{2}$, instead of SE D, did not induce high amounts of RF (data not shown), although these two superantigens significantly stimulated clone BAJ 1-107 to proliferate. Of the nine T cell clones shown in Table I, six were able to help B cells to induce RF secretion (Fig. 1, Fig. 3, Fig. 4, and data not shown). In addition to BAJ 1-107, the V $\beta 6^{+} \mathrm{T}$ cell clone STAP 4-404 provided help for RF production, but only proliferated marginally to SE $\mathrm{D}$. These data suggest that the selectivity of SE D may relate to an effect on B cells, and not only on T cells.

Variations of the $R F$ repertoire with distinct stimuli. To approach the question that SE $D$ triggered $B$ cell activation is restricted to IgM-producing $B$ cells, we have compared the IgM/IgG composition of the RF population produced in SE D and anti-CD3-stimulated T-B cell cultures. The results for B cells of five distinct donors are shown in Fig. 5. T cell help for all those cultures was provided by $T$ cell clone LAB 1-50. A mixture of IgM and IgG antibodies with RF activity was detected in both the anti-CD3 and the SE D driven cultures. Stimulation of $T$ cells by anti-CD3-mediated cross-linking resulted in low concentrations of RF. These anti-Fc antibodies included twice as much IgG antibodies as IgM antibodies. SE D
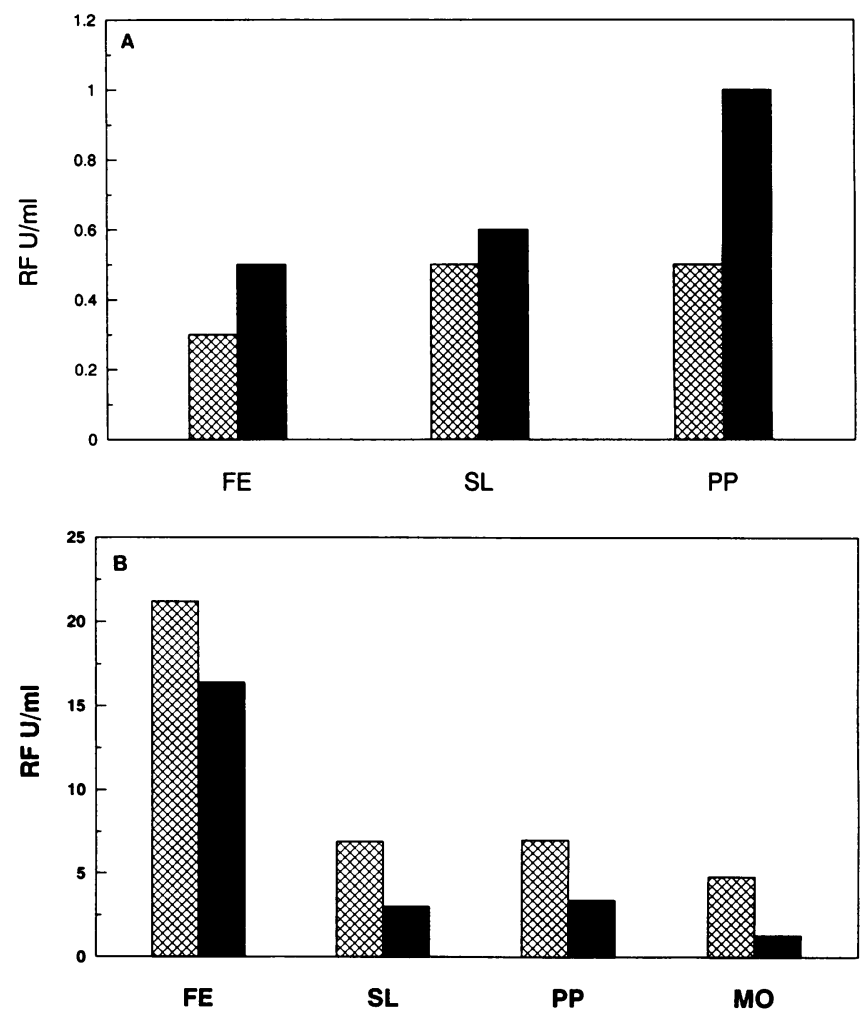

Figure 5. Isotype distribution of RF-induced by anti-CD3 or SE D. 1 $\times 10^{5}$ cloned T cells of clone LAB 1-50 were either activated with anti-CD3 $(A)$ or SE D $(B)$ and cultured with B cells from four different donors (SL and PP normal controls; MO and FE, RA patients). IgM (hatched bars) and IgG (solid bars) isotypes of RF were determined in an ELISA system applying rabbit IgG as antigen and developing with isotype specific antisera. 
greatly increased the production of IgM and IgG RF; however, the majority of RF antibodies secreted in the presence of SE D was of the IgM isotype. Nevertheless, SE D-induced RF also included high amounts of IgG antibodies, since considerably higher titers were induced, compared to the anti-CD3 driven cultures. The results indicate that a distinct subpopulation of B lymphocytes is responsive to the effect of SE D.

Stimulation by $S E D$ induces $R F$ secretions by a highly frequent $B$ cell. To confirm that SE D skews the repertoire of antibody specificities, we analyzed the secretion of immunoglobulins at different concentrations of B cells. B cells from the peripheral blood of an RA patient with active disease were co-cultured with T cell clone LAB 1-50 in the presence of SE D or immobilized anti-CD3. Culture supernatants were harvested after $10 \mathrm{~d}$ and analyzed for IgM, IgG, and RF. Results of cultures containing 10,000 to $156 \mathrm{~B}$ cells/well are shown in Fig. 6. In the anti-CD3 driven cultures, maximal amounts of 130 $\mu \mathrm{g} / \mathrm{ml}$ of total IgM and $200 \mu \mathrm{g} / \mathrm{ml}$ of total IgG were detected. IgM and IgG productions started to decline with less than 625 and $1250 \mathrm{~B}$ cells/culture, respectively. None of the anti-CD3 activated T-B co-cultures produced more than $0.5 \mathrm{U} / \mathrm{ml}$ RF activity. Induction of immunoglobulin synthesis in the SE Dstimulated cultures was less efficient. Maximal production of IgM and IgG in the presence of SE D required 10,000 purified $B$ lymphocytes/culture. In the SE D-triggered microcultures, RF activity was $\sim 14 \mathrm{U} / \mathrm{ml}$ at the higher $B$ cell concentrations with as few as $156 \mathrm{~B}$ cells still producing $2 \mathrm{U}$. Thus, the stimulation by SE D induces a clear shift in the repertoire of secreted antibodies. These data also demonstrate that the frequency of $B$ cells with the potential to produce RF circulating in the peripheral blood of RA patients is surprisingly high.

\section{Discussion}

Here we present multiple lines of evidence that one particular bacterial superantigen, SE D, triggers the selective production of RF in the presence of adequate T cell help. Thus, SE D not only circumvents the requirement for the $T$ helper cell to specifically recognize an antigen on the surface of the B cell, but in addition, shifts the repertoire of antibodies produced toward a preponderance of RF. The secretion of antibodies reactive to autologous IgG is a characteristic pathological finding in RA. The role of these autoantibodies in the chronic inflammatory process is not understood, and we do not believe that the articular inflammation is solely an antibody-mediated phenomenon. However, high titers of the autoantibodies are considered a prognostically poor sign (31). The mechanisms responsible for the continuous production of RF have not been identified, although there is convincing evidence that RF secretion is under the control of $T$ lymphocytes $(9-12,32)$. The $T$ cell requirements for RF synthesis have been especially studied in normal individuals in whom the transient production of the anti-IgG antibodies is detected during secondary $\mathrm{T}$ cell-dependent humoral responses (4). In their recent review, Chen et al. have discussed that essentially four different triggers of RF production may be functional (9). Aggregated IgG bound in antigenantibody complexes can induce RF production and a structural variant of autologous IgG could thus represent the continuous antigenic stimulus. Alternatively, exogenous antigens mimicking the RF binding sites on the Fc fragment might maintain the stimulation of Fc-specific $T$ and $B$ cells. Sequence analysis and the expression patterns of cross-reactive idiotypes on RF molecules support the notion that RF synthesis is an antigen-driven response. A more complex model interprets RF production as the result of an antiidiotypic regulation either through autologous antibody molecules or idiotype-specific regulatory T cells. Finally, polyclonal B cell activators have been suggested as chronic RF inducers. Here, we suggest yet another model attempting to explain why patients with RA fail to downregulate the autoantibody production. Our data demonstrate that a bacterial superantigen in the presence of appropriate $T$ helper cells selectively induces $\mathrm{RF}^{+} \mathrm{B}$ cells to secrete

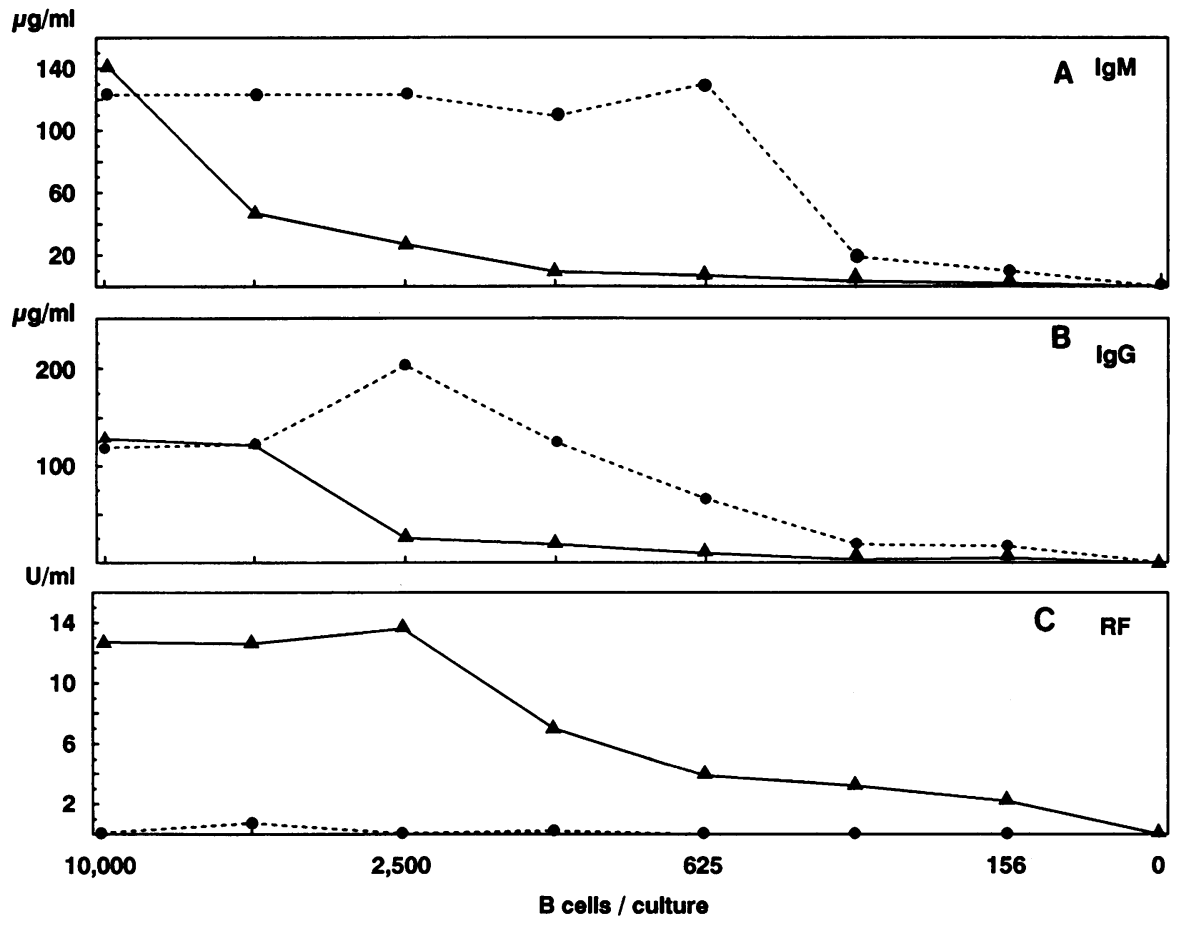

Figure 6. High frequencies of RF producing peripheral B cells in RA patients. B lymphocytes were isolated from the peripheral blood of a patient with active RA (HLADR 4/5) and titrated from 10,000 cell/well to 156 cells/well. Help was provided by $T$ cell clone LAB 1-50. The cultures were either stimulated with immobilized anti-CD3 $(\bullet-\cdots)$ or $0.5 \mu \mathrm{g} / \mathrm{ml} \mathrm{SE} \mathrm{D} \mathrm{( \triangle} \mathrm{---.} \Delta)$. Culture supernatants were harvested after $11 \mathrm{~d}$ and analyzed in parallel for $\operatorname{IgM}(A)$, $\operatorname{IgG}(B)$ or $\mathrm{RF}(C)$. Anti-CD3 stimulation did not induce relevant titers of RF. Significant IgM and IgG production required approximately 312 B lymphocytes. Higher numbers of B cells (1250-2500/culture) were necessary for significant levels of SE $D$ induced IgM and IgG. Cultures with 156 $B$ cells produced $R F$ indicating that the vast majority of SE D supported Ig production at that cell concentration represented $\mathrm{Fc}$ binding autoantibodies and that the frequency of $\mathrm{RF}^{+}$peripheral $\mathrm{B}$ cells was surprisingly high. 
antibodies. Our in vitro T-B cell system mimics the conditions in the RA patient in so far that RF synthesis is not the result of polyclonal hyperproduction of immunoglobulins, but rather a significant shift in the antibody repertoire toward the synthesis of Fc-reactive specificities.

Recently, bacterial superantigens have attracted attention because of their unique role in $T$ cell activation (18-24). They are potent activators of high frequencies of $T$ lymphocytes and their action is restricted through the $\mathrm{V} \beta$ element of the TCR. Efficient cross-linking of the TCR, however, requires complexing to an MHC class II molecule on the surface of an antigenpresenting cell. Geha et al. have studied the biological consequences of the HLA-superantigen-interaction for the B lymphocyte and have demonstrated that the binding of the toxic shock syndrome toxin 1 to HLA-DR molecules induces transmembrane signals that act as comitogens to B cells triggered with anti-human IgM antibodies $(25,26)$. Toxic shock syndrome toxin failed to induce the differentiation of B lymphocytes into Ig secreting cells in the absence of exogenous $\mathrm{T}$ cells. In the T-B cell co-culture system described here, bacterial enterotoxins significantly varied in their biological functions. Whereas $S E C_{1}$ and $S E C_{3}$ were rather inefficient for antibody production, SE D strongly induced $B$ cell activation. The SE D-induced B cell stimulation was distinguished from a polyclonal $B$ cell stimulation mediated through a $T$ cell population stimulated by anti-CD3. In anti-CD3 driven cultures, RF activity was minimal and probably represented the result of random and polyclonal B cell stimulation. In contrast, SE D-driven cultures did contain IgM and IgG antibodies and their repertoire was clearly shifted toward the production of RF.

RF synthesis has been attributed to a particular B cell subset, the $\mathrm{CD}^{+} \mathrm{B}$ cells $(6,7) \cdot \mathrm{CD}^{+} \mathrm{B}$ cells release natural antibodies, including the majority of Fc binding antibody specificities and other autoantibodies, mainly of the IgM isotype. Provided that the selectivity of SE D relates to a preferential triggering of $\mathrm{CD}^{+} \mathrm{B}$ cells, then this $\mathrm{B}$ cell subset would be characterized by a particular responsiveness to the bacterial superantigen. We do not have evidence that in the SE D driven cultures, other autoantibodies, like antinuclear factors as demonstrated in an assay system applying Hep 2 cells, are induced (data not shown). In addition, analysis of the RF isotypes in the SE D-induced culture supernatants revealed a significant portion of IgG antibodies (Fig. 5) which resembles the secretion pattern of $\mathrm{CD5}^{+} \mathrm{B}$ cells in RA patients. In contrast to normal individuals, the RF secreted by $\mathrm{CD}^{+} \mathrm{B}$ cells in RA patients represents a heterogenous population with different isotypes, including $\mathrm{IgG}$ antibodies. We are currently focusing our experiments on identifying the B cell subset specifically activated by SE D, and will address the question how SE D induces the differentiation into IgG-RF producing cells.

Previous reports using plaque forming assays have shown that the number of RF producing $B$ cells circulating in the peripheral blood is very low $(33,34)$. In general, significant amounts of RF were only produced in patients with more active disease. Data shown in Table II, however, indicate that under conditions of optimal stimulation by SE D, similar concentrations of RF are synthesized by $B$ cells of normal individuals and RA patients. Under these conditions, the frequency of $\mathrm{B}$ cells capable of RF production is extremely high; only $150 \mathrm{~B}$ cells were necessary to induce detectable amounts of RF in an RA patient (Fig. 6). These data raise the possibility that the B cell compartment able to release antibodies with $\mathrm{Fc}$ binding activity in normals is maintained in a state of anergy or is lacking appropriate $T$ cell help (35). SE D, together with appropriate helper signals, is obviously able to break the state of tolerance and induce the production of RF.

Help provided by $\mathrm{CD}^{+} \mathrm{T}$ cells was an absolute requirement for SE D-induced RF production. We have attempted to substitute for $\mathrm{T}$ cell help by adding $\mathrm{T}$ cell-derived lymphokines to SE D-complexed B cells. Neither IL-2, IL-4, IL-6, nor a combination of these lymphokines, was sufficient to provide the required helper cell signals (data not shown). Optimal conditions to activate $\mathrm{RF}^{+} \mathrm{B}$ cells required direct contact between a $T$ cell and a $B$ cell in the presence of SE D. Cognate interaction between the HLA-DR molecule and the TCR leading to T cell proliferation did not appear to be required in the in vitro system. T cell clone BAJ 1-107 was able to provide help for RF production, although it did not proliferate in response to SE D, suggesting that SE D primarily acts on B cells. Alternatively, SE D was able to cross-link the TCR of T cell clone BAJ 1-107 and the MHC class II molecules on the surface of the B cell without initiating proliferation. Indeed, we have preliminary evidence that SE D can affect the function of T cell clone BAJ 1-107 (manuscript in preparation). Our finding that $\mathrm{SE} \mathrm{C}_{3}$ and $\mathrm{SE} \mathrm{C}_{1}$ effectively induce $T$ cell proliferation but do not stimulate immunoglobulin secretion, lends further evidence to the hypothesis that different $\mathrm{T}$ cell functions are not necessarily linked in individual $\mathrm{T}$ cells, and that there exists a dichotomy of $\mathrm{T}$ cell proliferation and secretion of various lymphokines and help for B cells. These data suggest that signals provided to B lymphocytes by different bacterial toxins are not uniform, and that SE D may be unique in its action. The variety of biological consequences might relate to the interaction of certain superantigens with distinct $B$ cell subsets, although all B cells express HLA-DR molecules and thus are able to bind superantigens. Alternatively, the transmembrane signaling induced by microbial toxins in B lymphocytes may have distinct functional consequences depending on the B cell subset and the bacterial superantigen involved.

The selectivity of SE D to induce RF production also indicates the involvement of some, but not all, T helper cell populations in RF synthesis. This model is supported by the $\mathrm{V} \beta$-restricted $T$ cell activation by all known superantigens $(21,24)$. The functional role of endogenous and exogenous superantigens has been correlated to their binding for selected TCR V $\beta$ elements. A binding site expressed on the outside surface of the $\mathrm{V} \beta$ structure and encoded by the HVR 4 of the $\mathrm{V} \beta$ sequence has been identified for self-superantigens and $\mathrm{SE} \mathrm{C}_{2}$ and $\mathrm{SE} \mathrm{C}_{3}(23$, 24). Thus, the biological effects of a particular superantigen on an adult immune system are essentially influenced by the composition of the TCR repertoire. We have recently postulated that the HLA-DR association of RA can be explained by the regulatory role of HLA molecules in the formation of the patient's $T$ cell repertoire (36). HLA determinants associated with RA are expressed on the $\alpha$-helical portion of the HLA-DR molecule surrounding the antigen binding groove (37). Recognition of the HLA epitopes by alloreactive T cells clearly demonstrates that there exist structural constraints for the TCRHLA interaction leading to the preferential use of certain TCR $\mathrm{V} \beta$ families in $\mathrm{T}$ cell clones interacting with $\mathrm{RA}$-associated HLA determinants (Weyand, C. M., U. Oppitz, K. Hicok, and J. J. Goronzy, Manuscript submitted for publication.). We have demonstrated that TCR molecules utilizing the V $\beta 6$ segments fulfill these structural requirements and are dispropor- 
tionally used in such $\mathrm{T}$ cells. The majority of $\mathrm{V} \beta 6^{+} \mathrm{T}$ cell clones proliferate vigorously when they recognize SE D presented by HLA-DR molecules (28a). Thus, a model emerges in which SE $\mathrm{D}$ exhibits a preference for $\mathrm{V} \beta 6^{+} \mathrm{T}$ cells, which are predominantly recruited for the interaction with RA-associated HLA determinants. The present study raises several important issues regarding the potential roles of SE D in the regulation of RF production. The selective effect of SE D in the induction of RF synthesis in the T-B cell microcultures, combined with the stimulatory effect of SE D for $\mathrm{V} \beta 6^{+} \mathrm{T}$ cells specific for RA-associated HLA determinants, opens the possibility that the regulation of RF synthesis is linked to the T cell repertoire of the responder.

\section{Acknowledgments}

We are grateful to Dr. J. Katzmann for providing us with standard rheumatoid factor solutions, and Dr. H. Homburger for testing supernatants on Hep 2 cells. We acknowledge the advise of Dr. R. Kyle in establishing the ELISA assay systems. We thank Toni Buss for her devoted secretarial assistance. We appreciate the support of our patients and colleagues from the Division of Rheumatology.

This work was supported by the Mayo Foundation and the Minnesota Chapter of the Arthritis Foundation (MAF 76 and 77). Dr. Weyand is the recipient of an Arthritis Foundation Investigator Award.

\section{References}

1. Carson, D. A. 1989. Rheumatoid factor. In Textbook of Rheumatology. W. N. Kelley, E. D. Harris, Jr., S. Ruddy, C. B. Sledge, editors. WB Saunders, Philadelphia. 198-207.

2. Sasso, E. H., C. V. Barber, F. A. Nardella, W. J. Yount, and M. Mannik. 1988. Antigenic specificities of human monoclonal and polyclonal IgM rheumatoid factors: the $\mathrm{C} \gamma 2-\mathrm{C} \gamma 3$ interface region contains the major determinants. $J$. Immunol. 140:3098-3107.

3. Carson, D. A., P. P. Chen, R. I. Fox, T. J. Kipps, F. Jirik, R. D. Goldfien, G. Silverman, V. Radoux, and S. Fong. 1987. Rheumatoid factors and immune networks. Annu. Rev. Immunol. 5:109-126.

4. Welch, M. J., S. Fong, J. Vaughan, and D. Carson. 1983. Increased frequency of rheumatoid factor precursor B lymphocytes after immunization of normal adults with tetanus toxoid. Clin. Exp. Immunol. 51:299-304.

5. Williams, R. C., and H. G. Kunkel. 1962. Rheumatoid factor, complement and conglutinin aberrations in patients with subacute bacterial endocarditis. $J$. Clin. Invest. 41:666-675.

6. Hardy, R. R., K. Hayakawa, M. Shimizu, K. Yamasaki, and T. Kishimoto. 1987. Rheumatoid factor secretion from human Leu- $1^{+}$B cells. Science (Wash DC). 23:81-83.

7. Casali, P., S. E. Burastero, M. Nakamura, G. Inghirami, and A. L. Notkins. 1987. Human lymphocytes making rheumatoid factor and antibody to ssDNA belong to the Leu-1 ${ }^{+}$B-cell subset. Science (Wash. DC). 23:77-81.

8. Burastero, S., P. Casali, R. L. Wilder, and A. L. Notkins. 1988. Monoreactive, high affinity rheumatoid factors are produced by $\mathrm{CDS}^{+} \mathrm{B}$ cells from patients with rheumatoid arthritis. J. Exp. Med. 168:1979-1992.

9. Chen, P. P., S. Fong, and D. A. Carson. 1987. Rheumatoid factor. Rheum. Dis. Clin. North. Am. 13:545-567.

10. Koopman, W. J., and R. E. Schrohenloher. 1980. In vitro synthesis of IgM rheumatoid factor by lymphocytes from healthy adults. J. Immunol. 125:934939.

11. Tsoukas, C. D., D. A. Carson, S. Fong, J-L Pasquali, and J. H. Vaughan. 1980. Cellular requirements for pokeweed mitogen-induced autoantibody production in rheumatoid arthritis. J. Immunol. 125:1125-1129.

12. Coulie, P. G., and J. Van Snick. 1985. Rheumatoid factor (RF) production during anamnestic immune responses in the mouse. III. Activation of RF precursor cells is induced by their interaction with immune complexes and carrier-specific helper T cells. J. Exp. Med. 161:88-97.

13. Nardella, F. A., D. C. Teller, C. V. Barber, and M. Mannik. 1985. IgG rheumatoid factors and staphylococcal protein $\mathrm{A}$ bind to a common molecular site on IgG. J. Exp. Med. 162:1811-1824.

14. Mouritsen S. 1986. Rheumatoid factors are anti-idiotypic antibodies against virus-induced anti-Fc receptor antibodies. A hypothesis for the induction of some rheumatoid factors. Scand. J. Immunol. 24:485-490.

15. Weyand, C. M., and J. J. Goronzy. 1989. Seropositive rheumatoid arthritis is associated with T-cell epitopes encoded within the third hypervariable region of the HLA-DR1 and the HLA-DR4 haplotype. In Immunobiology of HLA. B. Dupont, editor. Springer-Verlag, New York. Vol. 2. 422.

16. Gregersen, P. K., J. Silver, and R. J. Winchester. 1987. The shared epitope hypothesis. An approach to understanding the molecular genetics of susceptibility to rheumatoid arthritis. Arthritis Rheum. 30:1205-1213.

17. Nepom, G. T., J. A. Hansen, and B. Nepom. 1986. The molecular basis for HLA class II associations with rheumatoid arthritis. J. Clin. Immunol. 7:1-7.

18. Kappler, J. W., U. Staerz, J. White, and P. C. Marrack. 1988. Self-tolerance eliminates T cells specific for Mls-modified products of the major histocompatibility complex. Nature (Lond.). 332:35-40.

19. MacDonald, H. R., R. Schneider, R. K. Lees, R. C. Howe, H. Acha-Orbea, H. Festenstein, R. M. Zinkernagel, and H. Hengartner. 1988. T-cell receptor V $\beta$ use predicts reactivity and tolerance to $\mathrm{Mls}^{\mathrm{a}}$-encoded antigens. Nature (Lond.). 332:40-45.

20. White, J., A. Herman, A. M. Pullen, R. Kubo, J. W. Kappler, and P. Marrack. 1989. The V $\beta$-specific superantigen staphylococcal enterotoxin B: stimulation of mature $\mathrm{T}$ cells and clonal deletion in neonatal mice. Cell. 56:27-35.

21. Janeway, C. A., J. Yagi, P. J. Conrad, M. E. Katz, B. Jones, E. Vroegop, and S. Buxser. 1989. T-cell responses to Mls and to bacterial proteins that mimic its behavior. Immunol. Rev. 107:61-88.

22. Pullen, A. M., T. Wade, P. Marrack, and J. W. Kappler. 1990. Identification of the region of $\mathrm{T}$ cell receptor $\beta$ chain that interacts with the self-superantigen Mls-1. Cell. 61:1365-1374.

23. Choi, Y., A. Herman, D. DiGiusto, T. Wade, P. Marrack, and J. Kappler. 1990. Residues of the variable region of the T-cell-receptor $\beta$-chain that interact with S. aureus toxin superantigens. Nature (Lond.). 346:471-473.

24. Kappler, J., B. Kotzin, L. Herron, E. W. Gelfand, R. D. Bigler, A. Boylston, S. Carrel, D. N. Posnett, Y. Choi, and P. Marrack. 1989. V $\beta$-specific stimulation of human T cells by staphylococcal toxins. Science (Wash. DC). 244:811813.

25. Mourad, W., P. Scholl, A. Diaz, R. Geha, and T. Chatila. 1989. The staphylococcal toxic shock syndrome toxin 1 triggers $\mathrm{B}$ cell proliferation and differentiation via major histocompatibility complex-unrestricted cognate T/B cell interaction. J. Exp. Med. 170:2011-2022.

26. Fuleihan, R., W. Mourad, R. Geha, and T. Chatila. 1991. Engagement of MHC-class II molecules by staphylococcal exotoxins delivers a comitogenic signal to human B cells. J. Immunol. 146:1661-1666.

27. Arnett, F. C., S. M. Edworthy, D. A. Bloch, D. J. McShane, J. F. Fries, N. S. Cooper, L. A. Healey, S. R. Kaplan, M. H. Liang, H. S. Luthra, et al. 1988. The American Rheumatism Association 1987 revised criteria for the classification of rheumatoid arthritis. Arthritis Rheum. 31:315-324.

28. Weyand, C. M., K. C. Hicok, and J. J. Goronzy. 1991. Nonrandom selection of T cell specificities in anti-HLA-DR responses: sequence motifs of the responder HLA-DR allele influence T cell recruitment. J. Immunol. 147:70-78.

28a.Goronzy J. J., U. Oppitz, and C. M. Weyand. 1991. Clonal heterogeneity of superantigen reactivity in human $\mathrm{V} \beta 6^{+} \mathrm{T}$ cell clones. Limited contributions of $\mathrm{V} \beta$ sequence polymorphisms. J. Immunol. In press.

29. Thiele, D. L., and P. E. Lipsky. 1985. The immunosuppressive activity of L-Leucyl-L-Leucine methylester: selective ablation of cytotoxic lymphocytes and monocytes. J. Immunol. 136:1038-48.

30. Iandolo, J. J. 1989. Genetic analysis of extracellular toxins of Staphylococcus aureus. Annu. Rev. Microbiol. 43:375-402.

31. Withrington, R. H., I. Teitsson, H. Valdimarsson, and M. H. Seifert. 1984. Prospective study of early rheumatoid arthritis. II. Association of rheumatoid factor isotypes with fluctuations in disease activity. Ann. Rheum. Dis. 43:679685.

32. Pereira, P., and A. Coutinho. 1989. I-E-linked control of spontaneous rheumatoid factor production in normal mice. J. Exp. Med. 170:1825-1835.

33. Vaughan, J. H., T. Chihara, T. L. Moore, D. L. Robbins, K. Tanimoto, J. S. Johnson, and R. McMillan. 1976. Rheumatoid factor-producing cells detected by direct haemolytic plaque assay. J. Clin. Invest. 58:933-941.

34. Petersen, J., C. Heilmann, O. J. Bjerrum, T. Ingemann-Hansen, and J. Halkjaer-Kristensen. 1983. IgG rheumatoid factor-secreting lymphocytes in rheumatoid arthritis: Evaluation of a haemolytic plaque-forming cell technique. Scand. J. Immunol. 17:471-478.

35. Pike, B. L., A. W. Boyd, and G. J. V. Nossal. 1982. Clonal anergy: the universally anergic B lymphocyte. Proc. Natl. Acad. Sci. USA. 82:3395-3399.

36. Weyand, C. M., and J. J. Goronzy. 1990. Disease-associated HLA determinants in patients with seropositive rheumatoid arthritis: functional role in antigen-specific and allogeneic T cell recognition. J. Clin. Invest. 85:1051-1057.

37. Brown, J. H., T. Jardetzky, M. A. Saper, B. Samraoui, P. J. Bjorkman, and D. C. Wiley. 1988. A hypothetical model of the foreign antigen binding site of class II histocompatibility molecules. Nature (Lond.). 332:845-850. 